\title{
Non-Patent Primary Literature: Journals, Conference Papers, Reports, Abstracts and Preprints
}

\author{
DANA L. ROTH
}

California Institute of Technology, Millikan 1-32, Pasadena, CA 91125, US Email: dzrlib@library.caltech.edu

\subsection{INTRODUCTION TO THE NON-PATENT PRIMARY LITERATURE}

Successful research efforts, in either academe or industry, require an awareness of the state of the art. This is necessary in order to identify previous research, to develop an understanding of the research problem, and to avoid unnecessary duplication of work. In addition, maintaining an on-going awareness of current literature in your area of chemistry, is crucial to career advancement. This is true for graduate students, whose theses must be based on unique research results, as well as for senior researchers who are able to secure grant funding and pursue exclusive technology rights only for original work.

Since there are currently $\sim 10000$ journals publishing 'chemistry' articles, the historical pattern of perusing the contents pages of a few crucial journals and communicating with colleagues must be supplemented by database searching. There are a variety of databases that can quickly provide a review of recent developments and also offer current awareness alerts. 
As regards current awareness, it is important to recognize that both SciFinder and PubMed index basic bibliographic data, abstracts and cited references (if available) from articles as soon as they are posted to some journal websites, far in advance of their formal publication in a journal issue (i.e., complete with volume numbering and pagination.

This is in contrast with Web of Science, Scopus and Reaxys, which only index articles after they are formally published, which is also when SciFinder and PubMed provide full indexing.

\subsection{JOURNALS}

\subsubsection{Introduction}

While the scientific journal literature ${ }^{1}$ has largely completed a conversion from print to electronic format, there is currently a dichotomy faced by researchers accessing the primary journal literature. Those with convenient access to university-subscribed resources are able to display or download full text articles through Google/Google Scholar or via indexing and abstracting services that make use of link resolvers, such as SFX. ${ }^{2}$

Researchers, primarily at small companies lacking subscribed resources, however, have several viable options: obtain personal journal subscriptions or copies of articles directly from publishers, or subscribe to pay-per-view services, such as DeepDyve, ${ }^{3}$ which offer both rental and purchase options.

Fortunately, for biomedical chemistry researchers, the National Library of Medicine developed PubMed Central ${ }^{4}$ in 2000 as a full-text archive of freely available biomedical and life sciences journal literature. In 2008, with the adoption of the NIH Public Access Policy, ${ }^{5}$ final peerreviewed journal manuscripts from NIH funded research must be deposited, upon acceptance for publication, in PubMedCentral. Most of the NIH deposited articles, however, have a short (6-12 month) embargo, because of journal publisher policies. The NIH requirement for full public access is no later than 12 months after publication.

In addition, there are quite a number of journals that are published on an open-access basis. These journals are listed in the Directory of Open Access Journals (DOAJ), ${ }^{6}$ which is both searchable and browsable at the journal-title level and searchable (author, title, abstract etc.) at the article level.

This access dichotomy has resulted in an on-going struggle between readers and journal publishers over the question of subscription access and open access. 


\subsubsection{Open Access}

The question of open access ${ }^{8 \mathrm{a} . \mathrm{b}}$ originally developed from the perceived need for patients to have full access to the medical literature. This may have resulted from a general ignorance that journal article abstracts are freely available from either publisher websites or freely accessible databases, such as PubMed and Google Google Scholar.

Responsible publishers, whether via subscriptions or open access, provide essential added value to author manuscripts (i.e., editorial acceptance, peer review, copy editing, electronic formatting and long-term storage), and providing these services obviously requires adequate compensation. ${ }^{9 a, b}$ The question then becomes whether dissemination of scientific results through journal articles is best served by subscription access, requiring either a personal or institutional (reader-pays) subscription, or by open access (author pays), which is dependent on author and/or funding agency payment for the publication services.

Historically, many U.S. society publishers offered a hybrid model that combined reasonable subscription prices with author page charges. This model continues today for a few titles (e.g., Phys. Rev. Letters, J. Biol. Chem.). However, for many society publishers (e.g., ACS) this model has been virtually undone by the rapid rise of commercially published journals that offer increasingly expensive institutional subscriptions, without assessing author page charges.

One interesting option, first offered by the American Physical Society and now adopted by the American Astronomical Society, is to allow onsite public and high school library access to complete archives of their journals. The APS goal 'is to provide access to everyone who wants and needs our journals,. 9 This access is available at no cost, providing that libraries accept a site license and provide the IP addresses for their public-use computers.

There are essentially two versions of open access. 'Gold' is defined as open access to the version of record, the final published version available directly from the journal publisher. The cost of Gold open access is the author's responsibility, and varies considerably, from $\sim \$ 1000$ for society-published journals (e.g., PNAS, ACS members at subscribing institutions) to $\sim \mathrm{\$} 3000$ for society-published journals (e.g., ACS nonmember at non-subscribing institutions) and commercially published journals (e.g., Elsevier, Springer). The risks of Gold open access are: (1) the 'culling of the scientific record', by making it difficult for those who are not research funded to publish their work; and (2) the concern that, by paying to publish, acceptance rates may rise at the expense of 
quality. This is a concern that is exacerbated by the reported existence of predatory publishers operating essentially as vanity presses. ${ }^{10}$

One significant 'Gold' variation is the American Chemical Society, which gives authors a unique AoR (Author of Record) URL link allowing 50 downloads during the first year after publication and unlimited downloads in succeeding years. These URLs can be posted on an author's webpage or institutional repository.

'Green' open access is based on authors, or their surrogates, posting their final peer-reviewed and accepted-for-publication manuscripts on a personal or institutional website. Author participation in providing this access, while generally permitted by responsible publishers, has been difficult to achieve in the absence of institutional mandates.

While there is continuing pressure for the provision of Gold open access, especially for publications resulting from government-funded research, further discussion is beyond the scope of this chapter. Additional information is available in both The STM Report and the Finch Report. ${ }^{11}$

\subsubsection{Indexing and Abstracting Services}

Journal articles are indexed and searchable in both subscription databases, e.g., SciFinder and Web of Science (WoS); freely available databases, e.g., PubMed and Google/Google Scholar; and most publisher websites, e.g., SpringerLink and ACS Publications. ${ }^{12}$ Each database has unique criteria for both journal selection and subject coverage. ULRICHSWEB is a global serials directory that provides detailed information on over 300000 periodicals, including abstracting and indexing coverage. ${ }^{13}$

SciFinder is the electronic version of Chemical Abstracts, which ceased publication, in print, at the end of 2009. SciFinder consists of multiple files, with the CAplus file ${ }^{14}$ containing bibliographic data, indexing terms, abstracts and related data, for each record. The CAplus file, which currently has $>36$ million records, is unique in that it extends the definition of chemistry beyond the traditional areas of: analytical; applied; biological; inorganic; macromolecular; organic; and physical chemistry to include the chemical aspects of astronomy, structural biology, education, engineering, economics, geology, history, mathematics, medicine and physics.

Chemical Abstracts has a long history of indexing a wide variety of publications: journal articles, chemical patents, conference papers, dissertations, technical reports, technical disclosures and chapters from monographs. In 1994, CA began abstracting 1580 core chemical 
journals ${ }^{15}$ cover-to-cover, providing 'in-process' records prior to full indexing. Thus, bibliographic and abstract information is generally available in CAplus within 8 days of receipt, with full indexing completed within 30-90 days. This explains why an author or keyword search will retrieve some very recent papers, while a substance search will not. For patents from the primary patent offices (US, EP, WO, JP, UK, FR and DE) bibliographic and abstract (machine translations for JP and DE) information is available within two days of publication and full indexing is completed within 27 days. ${ }^{16}$ CAplus has also extended the contents of the print Chemical Abstracts, to include records for over 224000 journal articles, abstracts and patents published before 1907. ${ }^{17}$

The CAS Source Index $(\mathrm{CASSI})^{18}$ is a cumulative record of publications indexed and abstracted in SciFinder. It is freely searchable by title, abbreviation, ISBN or ISSN. CLICAPS ${ }^{19}$ is a university library catalog that has journal records cataloged according to CASSI, with full title, extensive abbreviations, and succeeding and preceding titles.

Web of Science $^{20}$ is a journal-article database containing bibliographic data, indexing terms, abstracts, and related data. Web of Science originated the concept of cited reference searching and offers both 'Cited Reference Searching' (as they appear in the various journal article reference lists) as well as 'Cited By' links (to correctly cited references that are linked to their respective Web of Science records). Selection of the journals indexed in Web of Science ${ }^{21}$ is generally based on each journal's Impact Factor. ${ }^{22}$ The Conference Proceedings Citation Index ${ }^{23}$ and the Book Citation Index ${ }^{24}$ are also available, within Web of Science, in a fully integrated package.

PubMed $^{25}$ is a freely available journal-article database on Medline, a bibliographic database with a subject focus on all aspects of medicine, and its related sciences and engineering. Medline ${ }^{26}$ currently indexes $\sim 5600$ international journals and has $\sim 20$ million records dating from 1946, and is adding $\sim 3000$ records each day. Medline records are extensively indexed with NLM Medical Subject Headings (MESH), ${ }^{27}$ a controlled vocabulary thesaurus. In addition to Medline, PubMed also contains in-process records prior to Medline indexing, and records for out-of-scope articles in Medline journals (i.e., general science and chemistry) whose life science articles are indexed with MESH for Medline. When searching PubMed, 'Advanced Search' is strongly recommended. After a search, clicking on the title of an article, in the initial display, displays the complete record, which includes the Abstract, Related citations, Cited by (PubMedCentral) articles, etc. A SciFinder search also includes results from a 'Medline' database, which is essentially the same as PubMed. ${ }^{28}$ 
Google/Google Scholar $^{29}$ are freely accessible web databases that index a wide range of scholarly literature but have a variety of unstated limitations. As opposed to other databases, Google/ Google Scholar provide no listing of the publications that are indexed. Use of both Google Scholar's Advanced Scholar Search and Scholar Preferences is strongly recommended. The list of results is ranked according to a variety of factors, ${ }^{30}$ and provides 'Cited By' links to references in the database, related articles, and links to multiple versions (records of the article in a variety of databases, e.g., PubMed, NASA ADS, JSTOR). Google is very often a good resource for the full text of specific articles, which may be retrieved by searching with full article titles.

In contrast to the comprehensive A\&I services, whose indexing is based on bibliographic and abstract information supplied by publishers, many publishers also provide databases that offer full-text searchable content limited to their publications.

Science Direct ${ }^{31}$ is a representative example of a major commercial publisher database. It currently provides searchable access to nearly 10 million articles and chapters (adding about 500000 records per year), from over 2500 journals and 10000 books. Book and journal titles are both browsable and searchable, and the article/chapter contents are full-text searchable. While the full text requires subscription access, the abstracts, figures and tables are freely displayed. From the abstract display, an article's corresponding record in Scopus (Elsevier's equivalent to Web of Science) is available. The "View Record in Scopus' displays the two most recent citing articles, and the five most recent articles by the original article's authors. Other commercial publisher databases include SpringerLink and the Wiley Online Library (which includes journals published by the Gesellschaft Deutscher Chemiker, ChemPubSoc Europe and the Asian Chemical Editorial Society).

ACS Publications ${ }^{32}$ is representative of non-profit society publishers. It currently provides full-text searchable access to over 1 million articles from journals, and chapters in its ACS Symposium Series and Advances in Chemistry. The ACS Pubs webpage provides an alphabetical listing of titles and a default search box for full-text searching of keywords, citations, DOI, or 'within a specific subject'. 'Advanced Search' offers Boolean, phrase, wildcard, stemming and limiting a search to a specific journal title. Full-text article access requires a subscription but abstract display is free. ACS has recently announced new member benefits, which include online access (limited to 48 hours from initial article request) to any 25 articles from ACS Journals, ACS Symposium Series, and C\&EN 
Archives. Another important society publisher is the Royal Society of Chemistry, which offers full-text searching for its journal articles and book chapters. ${ }^{33}$

\subsubsection{Current Awareness}

Awareness of current research results is an essential component of any research program. In the print journal/database era, librarians routinely routed journal issues and/or photocopies of their contents, and researchers routinely visited the library to peruse recent issues and/or maintained personal subscriptions. Since then, with the enormous increase in publication and the transition to electronic journals and databases, and widespread use of laptops and mobile devices, these practices have been replaced with email or RSS alerts from online databases and/or directly from journal publishers.

The following databases provide users with options to save search statements and have them run automatically on a regular schedule. The journal publisher websites offer e-mail announcements for each new journal issue or book volume.

\section{SciFinder}

https://scifinder.cas.org

SciFinder offers an 'add KMP Alert' link, which can be activated from any 'references' list. Clicking this link opens a dialog box for entering: Title, Description, Duration, and Frequency (weekly or monthly), as well as an option to exclude previously retrieved references (since, for example, many ACS articles are indexed ahead of print, and require updating).

\section{Web of Science}

http://apps.webofknowledge.com

Web of Science (personal login required) offers a variety of search 'alerts', (e.g., author, topic, address, or cited reference). Following a search, a search 'alerts' is initiated by clicking 'Search History' (top menu bar). The last query on the 'Search History' page will be used to generate the 'alert'. Then click 'Save History/Create Alert'. After editing the fields on the 'Save Search History' page, check-off' Send Me E-mail Alerts' and click 'Save'. A 'saved' search strategy cannot be edited. It must be cancelled and replaced with a new search strategy. Web of Science also offers cited reference 'alerts'. Each WoS record has a 'Create Citation Alert' tab that, when clicked, will result in an e-mail 
alert being sent out each time this article is cited by a newly published article. Cited reference 'alerts' are very useful for identifying research articles that have recently cited a previously published article.

\section{PubMed}

http:/www.ncbi.nlm.nih.gov/sites/entrez

PubMed offers 'My NCBI', which can be used to save search strategies, search results and a bibliography, and has an option to automatically run saved searches and email the results. First click on the 'My NCBI' tab and register. After signing in, click the 'My NCBI' tab, then run a search and click 'Save search'. The web page screens that follow walk the user through the process that results in monthly, weekly or daily updates.

\section{Google Alerts}

http:/www.google.com/alerts

'Google Alerts' are based on the most recent Google results (web, news, blogs, videos, discussion or books). Email updates are based on entering a 'Search query', which can be set to search 'Everything' or limited to a specific category. Alerts are sent: 'As-it-happens'; Once a day; or Once a week and can be limited to either 'Only the best results' or 'Everything'.

\section{Science Direct}

http://www.sciencedirect.com/

Science Direct offers 'My alerts' (following free registration). 'My alerts' choices include: Search alerts (define and run a search, then save the search as a Search Alert); topic alerts (select a pre-defined topic, e.g., electrochemistry, organic chemistry etc.); and volume/issue alerts (for individual journal issues or book volumes, as published).

\section{ACS Publications}

http://pubs.acs.org/

The ACS Publications home page offers 'e-alerts' that are either ASAP Alerts (notification when individual articles are released on the web), or TOC Alerts (notification when the table of contents for specific journal issues are posted). There is a 'Log In' button that leads to the ACS ID registration page (ACS membership is NOT required). After logging in, select the journals of interest, the desired alert frequency, and preferred email format. 


\subsubsection{Journal Impact}

Given the enormous number of research journals currently being published, it is important to have some measure of their quality. In this regard, the journal impact factor (IF) is frequently used by researchers as a criterion for selecting appropriate journals for research-publication submission. The IF was first introduced by Eugene Garfield, ${ }^{34}$ at the Institute for Scientific Information, in the Science Citation Index and is currently calculated on an annual basis for the journals indexed in the Web of Science, appearing in June of the following year in the Journal Citation Reports (subscription required). ${ }^{35}$

A journal's ISI Impact Factor ${ }^{36}$ is the average number of cites, in a given year, to the articles published in that journal during the two preceding years. For example, the Journal of the American Chemical Society averaged 9.907 cites in 2011 to each article published in its 2009 and 2010 issues. For example, to derive the Impact Factor for the Journal of the American Chemical Society:

\section{$\underline{64,111}$ cites to $(2009+2010)$ JACS articles $=9.907(2011$ JACS IF $)$}

$6,471(2009+2010)$ JACS articles

ISI also provides a five-year Journal Impact Factor, which is the average number of cites, for example, in 2010 to articles published in the 2005-2009 issues.

While generally valid, this averaging process can lead to some interesting anomalies. For example, Acta Crystallographica. Section A, which had an Impact Factor of $\sim 2$ from 2006 through 2008, saw a sudden increase to $\sim 50$ in 2009 and 2010 , as a result of one very heavily cited article published in $2008 .{ }^{37}$ Another example, of a rapid increase in a journal's Impact Factor, resulted from a single review article that cited over 400 recent articles in Cell Transplantation, almost doubling its Impact Factor (from 3.5 to 6.2). ${ }^{38}$

The Arizona State University Libraries has posted a 'Citation Counts' library guide for Web of Science, Google Scholar, and other alternatives. ${ }^{39}$ 'Citation Counts' are defined simply as the number of times a publication is cited by others. This measure is complicated by the fact that none of citation sources index all relevant publications. This very comprehensive guide provides both a listing of the many sources available for creating citation counts and a detailed explanation of their coverage and method of searching.

Recent competitors to the ISI Impact Factor are the SNIP (SourceNormalized Impact per Paper) and the SCImago Journal Rank (SJR). These databases attempt to normalize citing references across subject 
fields, thus allowing comparison of journals irrespective of their primary subject content. ${ }^{40}$

$\mathrm{SNIP}^{41}$ uses the ratio of citing references to the journal's citation potential (which is based on the citation pattern of the subject field), thus allowing comparison of diverse journals; whereas $\mathrm{SJR}^{42}$ is based on the idea that the quality and reputation of the citing journal should affect the value of its citations.

SNIP and SJR values are publicly accessible through JournalM3$\operatorname{trics}^{43}$ and are also integrated into the Scopus Journal Analyzer for its subscribers. ${ }^{44}$ They provide data on $\sim 18000$ journals, as well as proceedings and book series.

Another approach is reflected in the Eigenfactor Score, which is derived from the total number of citations to articles published in the previous five years in a given Journal Citation Report. The raw numbers are then refined so that journal self-citations are eliminated and citations from highly cited journals are given more significance.

Thomson Reuters includes Eigenfactor Scores in the Web of Knowledge Journal Citation Reports along with the corresponding Article Influence Score. From the WoK JCR website:

'The Article Influence determines the average influence of a journal's articles over the first five years after publication. It is calculated by dividing a journal's Eigenfactor Score by the number of articles in the journal, normalized as a fraction of all articles in all publications. This measure is roughly analogous to the 5-Year Journal Impact Factor in that it is a ratio of a journal's citation influence to the size of the journal's article contribution over a period of five years.... The mean Article Influence Score is 1.00. A score greater than 1.00 indicates that each article in the journal has an above-average influence. A score less than 1.00 indicates that each article in the journal has below-average influence. ${ }^{45}$

Eigenfactor (EF) and Article Influence (AI) scores are also available at the eigenFACTOR.org website. ${ }^{46}$ Care must be taken when searching with journal titles, since it is not obvious to which year the data refers. Clicking on the EF or AI values, however, currently displays graphical data plotted for 1997-2010 for both EF and AI, along with graphical data on cost-effectiveness for 2007-2010.

For comparison purposes, a selection of titles, and their 2011 (JCR) values are given in Table 2.1.

When comparing journals, it is very important to recognize that review journals are much more heavily cited and should not be 
Table 2.12011 impact metrics for four widely read, general chemistry journals.

\begin{tabular}{lrllll}
\hline Journal & ISI IF & SNIP & SJR & EF & AI \\
\hline Angew Chem IE & 13.455 & 3.963 & 1.123 & 0.51393 & 3.370 \\
J Am Chem Soc & 9.907 & 4.058 & 1.117 & 0.81677 & 2.792 \\
Chem Commun & 6.169 & 1.942 & 0.507 & 0.24077 & 1.547 \\
Chem-Eur J & 5.925 & 1.768 & 0.455 & 0.16880 & 1.527 \\
\hline
\end{tabular}

Table 2.2 2011 impact metrics for five review journals, covering various areas of chemistry.

\begin{tabular}{lcrrrr}
\hline Journal & ISI IF & SNIP & SJR & EF & \multicolumn{1}{c}{$A I$} \\
\hline Chem Rev & 40.197 & 15.865 & 3.791 & 0.21464 & 13.305 \\
Ann Rev Biochem & 34.317 & 10.131 & 7.805 & 0.05695 & 19.743 \\
Chem Soc Rev & 28.760 & 8.666 & 2.493 & 0.13670 & 8.069 \\
Ann Rev Phys Chem & 14.130 & 6.295 & 1.614 & 0.01687 & 7.467 \\
Coord Chem Rev & 12.110 & 4.195 & 0.789 & 0.04170 & 3.206 \\
\hline
\end{tabular}

compared to research journals. Although Angew Chem IE is primarily a research journal, its publication of review articles is one factor of its significant ISI IF.

Examples of important review journals, and their 2011 (JCR) data are given in Table 2.2.

\subsubsection{Article Impact}

The most commonly used metric for article impact is the h-index, ${ }^{47}$ named for its developer J.E. Hirsch ). The h-index, shown in a Web of Science Citation Report by an orange colored line, is based on a listing of publications ranked in descending order by the Times Cited count. To discount the effect of less significant publications, the articles in this ranking should be edited (e.g., to eliminate translations) and then limited to research and review articles. The numerical value of ' $h$ ' then is the number of articles (h) with at least (h) citations.

The h-index, however, tends to discount both highly and poorly cited articles. It rewards an author's longevity and productivity but penalizes authors with a relatively small number of highly cited articles (e.g., A. Einstein $[\mathrm{h}=53]$ and R.P. Feynman $[\mathrm{h}=33])$, whose $\mathrm{h}$-index is small compared with much more prolific authors (e.g., G. Whitesides $[\mathrm{h}=160])$ but whose average citations per article are 154,536 , and 120 , respectively. Please note that the h-index value, calculated from Web of Science data, is also a function of both the citation databases and the timespan, which can also be refined prior to the search to ensure an accurate and comparable set of publications, when comparing multiple authors. 
It can even be used to compare articles on a particular subject published in different journals, to help select high impact publishing venues.

The concept of altmetrics, ${ }^{48}$ for individual articles, provides a more immediate measure that supplements counting citations, by aggregating data from multiple online sources (e.g., tweets, blogs, bookmarks, citation counts etc.).

For example, Total Impact ${ }^{49}$ currently tracks a wide range of research output, e.g., papers, datasets, software, preprints and slides. Searchable terms include; DOI, PMID and URL and search results include HTML views, PDF views, citations and cited-in. On the Total Impact site, click on 'add to collection' and then click 'get my metrics' to see a sample search.

Harzing's Publish or Perish ${ }^{50}$ is a downloadable software program that retrieves and analyzes academic citations, using Google Scholar to obtain statistics that include: citations to and from journal articles, book chapters, patents, conference papers and technical reports (i.e., anything in Google Scholar).

Google Scholar Citations(GSC) ${ }^{51}$ provides a personalized citation analysis (following registration). It is possible to search for authors who have made their profile public in either GSC or Google Scholar. Google Scholar Citations is updated continually, allowing tracking of citations to your publications, graphing your citations over time and computing citation metrics. ${ }^{52}$ This data may be compromised, however, by "Ghost Authors ${ }^{, 53}$ that are variant forms of the same paper with citations that are mismatched by Google's crawler and parser programs.

A Google Scholar h-index Calculator is provided as a Firefox Add$\mathrm{On}^{54}$ but the results are problematic when refining search results to a specific author.

Several websites that host journal articles provide download data for individual articles that often far exceeds the citation counts in Web of Science or Scopus. Sensors \& Transducers Journal, which posts a rolling list of the 25 Top List of Most Downloaded Articles ${ }^{55}$ for the previous month, with a 'Previous' link at the bottom of the page for additional data. The Jefferson Digital Commons ${ }^{56}$ sends out monthly reports to authors, providing, for example, the total number of electronic downloads of papers published in the Special Libraries Association's Sci-Tech News. This service is based on the 'bepress Download Totals'. ${ }^{57}$

Since March 2009, the Public Library of Science (PLoS) ${ }^{58}$ has provided 'Article-Level Metrics (ALMs)', which currently include:

- article usage statistics (HTML page views, and PDF and XML downloads);

- citations (CrossRef, PubMed Central, Scopus, Web of Science, Google); 
- social networks (Facebook and Mendeley);

- blogs and media coverage (Google); and

- PLoS Readers (Rate this article, Comments \& Notes).

Many of these alternative methods for citation counts and journal rankings are compiled on a library guide ${ }^{39}$ that links to a variety of options and includes 'terms and definitions', 'tutorials' and 'further reading'.

\subsection{CONFERENCE PAPERS, REPORTS, ABSTRACTS AND PREPRINTS}

\subsubsection{Introduction}

Conference papers, reports, abstracts and preprints are commonly described as the 'Gray Literature', a term used by librarians for literature that was, for many years, often difficult to locate or obtain using commercial indexing and abstracting services. This situation has generally improved with the availability of the Conference Proceedings Citation Index (either as a separate subscription or in combination with Web of Science), and the resources provided by the British Library, ${ }^{59}$ which rightly claims to have the most comprehensive collection of publically available conference proceedings and reports.

A Caltech online library guide listing both open access conference paper websites (e.g., Elsevier Procedia - Chemistry, IOP Conference Series: Materials Science and Engineering) and indexing/abstracting databases (e.g., U.S. government, British Library) are available. ${ }^{60}$

The E-Print Network ${ }^{61}$ is a full-text searchable gateway to a worldwide collection of gray literature websites and databases of interest to DOE researchers. It contains preprints, reprints, technical reports and conference publications; primarily in physics, but also including chemistry, life sciences, materials science and energy research. It provides access to over 35000 websites and databases around the world, with over 5.5 million entries.

A comprehensive review article with links to free online science, technology and engineering resources is available. ${ }^{62}$

The National Technical Information Service (NTIS), the National Aeronautics and Space Administration (NASA) and the U.S. Department of Energy (DOE) all provide freely available online indexing/ abstracting services for research reports funded by the U.S. government.

Preprints, however, are not an established culture in chemistry. The American Chemical Society's journal editorial policy, in contrast with the ACS Symposium Series, treats preprints as prior publication. If a 
submitted article is found to have been posted on a preprint server, it will be withdrawn from consideration for publication in any of the ACS journals.

The ACS Symposium Series volumes, however, are often based on revised preprints that originally appeared in the following publications:

Preprints ... Division of Environmental Chemistry

Preprints ... Division of Fuel Chemistry

Preprints ... Division of Petroleum Chemistry

PMSE Preprints ... Division of Polymeric Materials Science \& Engineering

Polymer Preprints ... Division of Polymer Chemistry

Elsevier's Science Direct provided a preprint server but due to a lack of contributed articles stopped accepting new submissions on May 24, 2004.

\subsubsection{Indexing and Abstracting Services}

The following entries provide descriptions of resources that include chemistry-related information. While SciFinder indexes conference papers, reports, some arXiv and CERN preprints and ACS Meeting Abstracts, chemists interested in comprehensively searching for government sponsored research should take advantage of the specialty databases described below. Since each database will provide unique results, it is probably important to experiment with each one for maximum results.

ACS. Technical Programming Archive of Past National Meetings http:/portal.acs.org/portal/PublicWebSite/meetings/nationalmeetings/ programarchive/

This ACS website provides both browsable and searchable publically available access for each individual National Meeting since the 227th in March, 2004.

$\operatorname{arXiv}$

http://arxiv.org

The arXiv electronic preprint archive ${ }^{63}$ covers the fields of mathematics, physics, astronomy, computer science, quantitative biology, statistics and quantitative finance. While arXiv preprints are only of tangential 
interest to chemists, SciFinder has indexed all preprints (nearly 280000 ), beginning in 2000, in the following subject areas: Astrophysics, Condensed Matter, General Relativity and Quantum Cosmology, High Energy Physics, Nuclear Experiment, Nuclear Theory, Physics, Quantitative Biology and Quantum Physics.

BASE: Beilefeld Academic Search Engine http:/www.base-search.net/

BASE provides access to document servers that comply with the specific requirements of academic quality and relevance. It currently contains nearly 35 million documents (both journal articles and technical reports) from over 2000 content sources.

\section{Chemical Abstracts (SciFinder \& CAplus on STN) http:/www.cas.org/expertise/cascontent/caplus/confcov.html}

The CAplus file, in STN and SciFinder, has a long history of indexing conference papers from journal issues, separately published conference monographs, ACS National Meeting Divisional Symposia, as well as NTIS reports and, since 1995, have indexed and provided the full text of ACS National Meeting Abstracts, while maintaining its policy of not indexing publications simply consisting of abstracts. The 'Explore References' option in SciFinder allows selection of all or individual document types: Conference (which includes ACS Abstracts), Preprint, Report.

\section{Energy Citations Database (ECD)}

http:/www.osti.gov/energycitations

The ECD provides free public access to over 2.5 million report citations from 1943 to the present. It includes a full range of sci/tech research results of interest to the DOE covering the report literature, conference papers, journal articles, books, dissertations and patents. It includes the Nuclear Science Abstracts (1948-1976), and the ERDA/Energy Research Abstracts (1976-1994) databases.

\section{Google}

http://www.google.com

Confex.com provides for collection and management of presentations from hundreds of conferences annually. These presentations are indexed by Google and searchable by adding (confex.com and a sponsor acronym), to keywords and/or author names. For example, a search for 
Harry Gray's paper on Metal ligand triple bonds and the oxo wall, which was presented at the 2009 ACS meeting could be searched as:

Harry Gray triple 2009 (confex.com and ACS) which retrieves: http://oasys2.confex.com/acs/237nm/techprogram/P1231639.HTM

Information Bridge: DOE Scientific and Technical Information http://www.osti.gov/bridge/

Information Bridge provides freely available access to nearly 300,000 full text documents and citations for research reports funded by the DOE, from $1991+$. Subjects include 'chemistry', 'materials', 'renewable energy' etc.

International Nuclear Information System (INIS)

http:/www.iaea.org/inis/

INIS is the successor to the Atomindex, which first appeared on 1970. INIS is focused on peaceful uses of nuclear science and technology. The keyword default search is supplemented with an Advanced Search which allows both 'include' and 'exclude' options.

\section{NASA Technical Reports Server (NTRS)}

http:/ntrs.nasa.gov/search.jsp

The NTRS database has indexing/abstracting information for over 500000 aerospace citations (including 'chemistry and materials') with over 200000 that are online full-text. In addition, there is information on over 500000 images and videos. NTRS integrates the NACA (National Advisory Committee for Aeronautics) citations and reports (1916-1958) and the NASA (National Aeronautics and Space Agency) citations and documents (1958-present) with the NIX (NASA Image eXchange) collection of citations which has links to images, photos, movies and videos.

NTIS.gov

http://www.ntis.gov/

In addition to the NTIS bibliographic database which contains over 2 million records, this website also offers RSS current awareness feeds for nearly 40 subject areas, including 'Chemistry', 'Combustion', 'Energy' and 'Materials Sciences'. In addition, NTIS is the source for more than 150 subscriptions produced by U.S. government agencies.

Science Conference Proceedings

http://www.osti.gov/scienceconferences/

This is a distributed portal that provides access to sci/tech conference proceedings and papers published by both professional societies and 
national laboratories) that are of interest to the Department of Energy. Search options include: Select All or limited to specific societies (e.g., ACS, AOCS), national laboratories (e.g., EPRI, NIST) or the Energy Citations Database.

Science Research.com

http:/www.scienceresearch.com/scienceresearch/advancedsearch.html

ScienceResearch.com is a free, publicly available federated search engine. Federated searches are defined by their ability to submit search terms - in real time - to a pre-defined collection of databases. Results are then collated, ranked, and de-duplicated. Science Resarch.com offers a variety of text search and subject options.

\subsubsection{Current Awareness}

Most databases provide alert services which provide notification of newly added content. In addition, while conference papers often appear in regularly published journal issues, others are appearing in online (often open-access) monographic volumes. Many of these separately published volumes appear in publisher series, which provide new volume alerts, such as:

AIP Conference Proceedings (Subscription required) http://proceedings.aip.org/browse/new_titles

AIP (American Institute of Physics) Conference Proceedings covers worldwide scientific meetings which provide topical status reports on a wide variety of subjects.

IOP (Institute of Physics) Conference Series: Earth and Environmental Science

https:/conferenceseries.iop.org/theme/ees

An Open Access publication that complements a community web site, environmentalresearchweb.org and an open access journal, Environmental Research Letters.

IOP (Institute of Physics) Conference Series: Materials Science and Engineering

https:/conferenceseries.iop.org/theme/mse

An Open Access publication with conference papers on material science, physics, chemistry and engineering.

Journal of Physics: Conference Series

https:/conferenceseries.iop.org/theme/jpcs 
An Open Access publication with conference papers on physics, physical chemistry and biophysics.

Elsevier's Procedia Series

http://www.sciencedirect.com

A series of open-access conference proceedings on a wide variety of subjects, including: Energy Procedia, Procedia Chemistry, Procedia Environmental Sciences and Procedia Food Science.

EJP (European Journal of Physics) Web of Conferences http:/ www.epj-conferences.org/

Open-access proceedings in pure and applied physics, including materials science, physical biology, physical chemistry, and complex systems.

ACS (American Chemical Society Symposium Series [subscription]) http://pubs.acs.org/series/symposium

The ACS Symposium Series contains peer-reviewed papers based on presentations at ACS National Meeting symposia. The series covers a broad range of topics including: food chemistry, chemical education, organic chemistry, polymer chemistry, materials science etc. The first chapter in every volume of the series is freely available to view. Availability of all other chapters is based on institutional subscription or membership of the ACS.

\section{REFERENCES}

1. Scientific journal. Wikipedia, the Free Encyclopedia, http://en. wikipedia.org/wiki/Scientific_journal Accessed April 2, 2013.

2. SFX - the OpenURL link resolver and much more, http://www. exlibrisgroup.com/category/SFXOverview, Accessed April 2, 2013.

3. DeepDyve, http://www.deepdyve.com/, Accessed April 2, 2013.

4. PubMed Central. Wikipedia, the Free Encyclopedia, http://en. wikipedia.org/wiki/PubMed_Central, Accessed April 2, 2013.

5. NIH Public Access Policy, http://publicaccess.nih.gov/, Accessed April 2, 2013.

6. DOAJ - Directory of Open Access Journals, www.doaj.org/, Accessed April 2, 2013.

7. J. M. Drazen, G. D. Sprouse, J. W. Serene. Should Research Be More Freely Available? New York Times, January 23, 2012, http:// nyti.ms/edletter0112, Accessed April 2, 2013. 
8. M. Leptin. Open Access - Pass the buck, Science, 2012, 335, 1279. 10.1126/science.1220395; Open access Wikipedia, the Free Encyclopedia, http:/en.wikipedia.org/wiki/Open_access, Accessed April 2, 2013; Scholarship 2.0: An idea whose time has come, http:/ scholarship20.blogspot.com/2012/04/open-access-will-opennew-ways-to.html, Accessed April 2, 2013; Open access journal. Wikipedia, the Free Encyclopedia, http://en.wikipedia.org/wiki/ Open_access_journal, Accessed April 2, 2013.

9. (a) APS Online Journals Available Free in U.S. Public Libraries, http:/librarians.aps.org/public-access-announcement, Accessed April 2, 2013; (b) APS Online Journals Available Free in U.S. High Schools (February 9, 2011), http://pre.aps.org/highschool-accessannouncement, Accessed April 2, 2013.

10. Beall's List of Predatory, Open-Access Publishers, http://metadata. posterous.com/83235355, Accessed April 2, 2013.

11. The STM Report: An overview of scientific and scholarly journal publishing, http:/www.stm-assoc.org/2009_10_13_MWC_STM Report.pdf, Accessed April 2, 2013; Finch Report: Accessibility, sustainability, excellence: how to expand access to research publications. http:/www.researchinfonet.org/wp-content/uploads/2012/06/ Finch-Group-report-FINAL-VERSION.pdf, Accessed April 2, 2013.

12. PubMed, http:/www.ncbi.nlm.nih.gov/pubmed/, Accessed April 2, 2013; Google, http://www.google.com/, Accessed April 2, 2013; Google Scholar, http://scholar.google.com/, Accessed April 2, 2013; About Google Scholar, http://scholar.google.com/intl/en/scholar/ about.html, Accessed April 2, 2013; SpringerLink, http:// www.springerlink.com/, Accessed April 2, 2013; ACS Publications, http://pubs.acs.org/, Accessed April 2, 2013.

13. ULRICHSWEB: Global Serials Directory, http:/ulrichsweb. serialssolutions.com/, Accessed April 2, 2013.

14. SciFinder CAplus file, http:/www.cas.org/expertise/cascontent/ caplus/index.html, Accessed April 2, 2013.

15. CAplus Core Journal Coverage List, http:/www.cas.org/content/ references/corejournals, Accessed April 2, 2013.

16. CAS Coverage of Patents, http:/www.cas.org/content/references/ patentcoverage, Accessed April 2, 2013.

17. CAplus - Pre-1907 Coverage, http://www.cas.org/content/references/ capluspre1907, Accessed April 2, 2013.

18. CAS Source Index (CASSI) Search Tool, http://cassi.cas.org/ search.jsp, Accessed April 2, 2013.

19. CLICAPS (ETH Zurich) OPAC, http://www.clicaps.ethz.ch/en/, Accessed April 2, 2013. 
20. Web of Science, http:/wokinfo.com/products_tools/multidisciplinary webofscience/, Accessed April 2, 2013.

21. Thomson Reuters Master Journal List, http:/ip-science. thomsonreuters.com/mjl/, Accessed April 2, 2013.

22. Impact factor. Wikipedia, the Free Encyclopedia, http:/en.wikipedia. org/wiki/Impact_factor, Accessed April 2, 2013.

23. Conference Proceedings Citation Index (CPCI), http: /thomsonreuters. $\mathrm{com} /$ products_services/science/science_products/a-z/conf_ proceedings_citation_index/, Accessed April 2, 2013.

24. Book Citation Index (BCI), http://wokinfo.com/products_tools multidisciplinary/bookcitationindex/, Accessed April 2, 2013.

25. PubMed Fact Sheet, http:/www.nlm.nih.gov/pubs/factsheets pubmed.html, Accessed April 2, 2013.

26. Medline Fact Sheet, http:/www.nlm.nih.gov/pubs/factsheets/medline. html, Accessed April 2, 2013.

27. Medical Subject Headings (MESH) Fact Sheet, http://www. nlm.nih.gov/pubs/factsheets/mesh.html, Accessed April 2, 2013.

28. What's the Difference Between MEDLINE ${ }^{\mathbb{R}}$ and PubMed, http:/ www.nlm.nih.gov/pubs/factsheets/dif_med_pub.html, Accessed April 2, 2013.

29. Google Scholar. Wikipedia, the Free Encyclopedia, http:/en. wikipedia.org/wiki/Google_Scholar, Accessed April 2, 2013.

30. About Google Scholar, http://scholar.google.com/intl/en/scholar about.html, Accessed April 2, 2013.

31. Science Direct (Elsevier), http:/www.sciencedirect.com/, Accessed April 2, 2013; About Science Direct, http:/ www.info.sciverse.com sciencedirect/about, Accessed April 2, 2013; Science Direct (Intellogist), http:/www.intellogist.com/wiki/ScienceDirect, Accessed April 2, 2013.

32. ACS Publications. Wikipedia, the Free Encyclopedia, http:/en. wikipedia.org/wiki/American_Chemical_Society\#Journals_and_ magazines, Accessed April 2, 2013.

33. RSC Publishing: Advanced Search, http:/pubs.rsc.org/en/search advancedsearch, Accessed April 2, 2013.

34. E. Garfield. The History and Meaning of the Journal Impact Factor. JAMA, 2006, 295, 90. http://jama.jamanetwork.com/article. aspx?articleid $=202114$; E. Garfield. The Agony and the EcstasyThe History and Meaning of the Journal Impact Factor. Presented at the International Congress on Peer Review And Biomedical Publication, Chicago, IL, September 16, 2005. http://garfield. library.upenn.edu/papers/jifchicago2005.pdf. 
35. Journal Citation Reports, http://webofknowledge.com/JCR, Accessed April 2, 2013.

36. Impact Factor. Wikipedia, the Free Encyclopedia, http://en.wikipedia. org/wiki/Impact_factor, Accessed April 2, 2013.

37. At the time of this writing, G. M. Sheldrick. A short history of SHELX. Acta Crystallogr. 2011, 64, 112. (http:/scripts.iucr.org/cgibin/paper?sc5010) had been cited 21,913 times in the Web of Science.

38. The Emergence of a Citation Cartel. MetaFilter: community weblog, http:/ www.metafilter.com/115956/The-Emergence-of-a-CitationCartel, Accessed April 2, 2013.

39. Citation Research (Arizona State University Library), http: libguides.asu.edu/content.php?pid $=11186 \&$ sid $=74734$, Accessed April 2, 2013.

40. M. E. E. Falagas. Comparison of SCImago journal rank indicator with journal impact factor. The FASEB Journal, 2008, 22, 2623; P. Jacso. Comparison of journal impact rankings in the SCImago Journal \& Country Rank and the Journal Citation Reports databases. Online Information Review, 2010, 34, 642, http://www. emeraldinsight.com $/$ journals.htm? articleid $=1876484 \&$ show $=$ pdf.

41. About SNIP, http://www.journalmetrics.com/snip.php, Accessed April 2, 2013.

42. About SJR, http://www.journalmetrics.com/sjr.php, Accessed April 2, 2013.

43. JournalM3trics, http://www.journalmetrics.com/, Accessed April 2, 2013.

44. Scopus Journal Analyzer, http:/www.info.sciverse.com/scopus/ scopus-in-detail/tools/journalanalyzer/, Accessed April 2, 2013.

45. Journal Citation Reports Help, http:/admin-apps.webofknowledge. com/JCR/help/h_eigenfact.htm, Accessed April 2, 2013.

46. eigenFACTOR.org, http://www.eigenfactor.org/, Accessed April 2, 2013.

47. h-index. Wikipedia, the Free Encyclopedia, http:/en.wikipedia.org/ wiki/H-index, Accessed April 2, 2013.

48. J. Howard. Scholars Seek Better Ways to Track Impact Online. The Chronicle of Higher Education, http://chronicle.com/article/ As-Scholarship-Goes-Digital/130482/, Accessed April 2, 2013.

49. Total Impact, http:/total-impact.org/, Accessed April 2, 2013.

50. Harzing, A. W. (2007) Publish or Perish, http://www.harzing.com/ pop.htm, Accessed April 2, 2013.

51. Google Scholar Citations, http://scholar.google.com/citations, Accessed April 2, 2013; I. F. Aguillo. Is Google Scholar Useful for 
Bibliometrics? A Webometric Analysis. Scientometrics, 2012, 91, 343, http://scholarship20.blogspot.com/2012/04/is-google-scholaruseful-for.html.

52. P. Jacso and Google Scholar Author, Citation Tracker: is it too little, too late?, Online Information Review, 2012, 36, 126.

53. P. Jacso, Google Scholar's Ghost Authors, Library Journal, 2009, 134, 26, http:/www.jacso.info/PDFs/jacso-google-scholars-ghostauthors.pdf.

54. Google Scholar h-index Calculator, https:/addons.mozilla.org/ en-US/firefox/addon/scholar-h-index-calculator/, Accessed April 2, 2013.

55. 25 Top List of Most Downloaded Articles, http://www. sensorsportal.com/HTML/DIGEST/Top_articles.htm, Accessed April 2, 2013.

56. Jefferson Digital Commons, http://jeffline.tju.edu/Publishing jdc.html, Accessed April 2, 2013.

57. The Berkeley Electronic Press Download Totals, http://www. bepress.com/download_counts.html, Accessed April 2, 2013.

58. Public Library of Science (PLoS), http:// www.plos.org/, Accessed April 2, 2013.

59. British Library. The Conference Collections, http:/www.bl.uk reshelp/atyourdesk/docsupply/collection/confs/index.html, Accessed April 2, 2013; British Library, Reports. http:/www.bl.uk reshelp/atyourdesk/docsupply/collection/reports/index.html, Accessed April 2, 2013.

60. Conference Papers/Reports/Abstracts - Publications \& Databases, http:/libguides.caltech.edu/aecontent.php?pid $=81988, \quad$ Accessed April 2, 2013.

61. E-Print Network, http://www.osti.gov/eprints/, Accessed April 2. 2013.

62. N. Tchangalova and Francy Stilwell, Search engines and beyond: A toolkit for finding free online resources for science, technology and engineering, Issues in Science and Technology Librarianship, Spring 2012, http:/www.istl.org/12-spring/internet1.html.

63. arXiv, http://en.wikipedia.org/wiki/ArXiv, Accessed April 2, 2013. 